\title{
Second and Foreign Language Education. Nelleke Van Deusen- Scholl \& Stephen May (Eds.), 3rd ed., Vol. 4. Cham, Switzerland: Springer International Publishing, 2017. 458 pp. ISBN 978-3-319-02245-1
}

\author{
Lilia Raitskaya \\ Moscow State Institute of International Relations (MGIMO University) \\ Correspondence concerning this article should be addressed to Lilia Raitskaya, MGIMO-University, 76 \\ Prospekt Vernadskogo, Moscow, Russian Federation, 119454.E-mail: 1.raitskaya@mail.ru
}

\begin{abstract}
Second and Foreign Language Education is one of the ten volumes of the Encyclopedia of Language and Education published by Springer International AG in 2017. The volume is part of the third edition of the Encyclopedia and describes recent developments in language and education. Those reflect the internationalism and versatility of the field, according to the late David Corson who became the first editorin-chief of the initially eight-volume Encyclopedia in 1997. With the 2nd edition in 2008, it expanded to ten volumes by adding new books on language ecology and language socialization.

The current 3rd edition overviews a wide scope of topics, including new trends such as the influence of migration, modification processes across the globe, the emergence of multilingualism, its educational implications and consequences, academic approaches to technology, virtual environments, multimodality, etc. The new edition aims to provide a most impressive outline, with authors contributing to the volume from all over the world.

The Second and Foreign Language Education volume (3rd ed.) has been thoroughly revised and updated to cover major themes, which are organized into four parts of the book: Part One. Theoretical Underpinnings. Part Two. Current Approaches to Second and Foreign Language Education. Part Three. International Perspectives on Second and Foreign Language Education. Part Four. Teacher Preparation and Professional Development.
\end{abstract}

Part One sets the stage for an exploration of theoretical base for second and foreign language education. In Part One headlined Theoretical Underpinnings, readers may find a chapter authored by Claire Kramsch and devoted to applied linguistics as a multidisciplinary field of research and the ways it explains the processes of acquiring, learning, studying foreign languages as well as the principles of foreign language education in our globalized world.

Sandra Lee McKay in the chapter Socioliguistics and Language Education shows the major strands of investigation in sociolinguistics (language variation, language contract, and language change) and discusses their pedagogical implications in the light of different language resources, different pragmatic norms, and linguistic diversity.

The next three chapters deal with varied theories related to second language (L2) learning (by Rebecca L.Oxford); potential relationships between bilingualism and the process of L2 acquisition (by Andrew Lynch); and the application of Vygotskyan and neo-Vygotskyan understandings of sociocultural theory approaches to various areas of L2 acquisition (by Amy Snyder Ohta).

Part Two Current Approaches to Second and Foreign Language Education comprises ten chapters and starts with the chapter, in which Friedericka L. Stoller and Shannon Fitzsimmons-Doolan dwell upon contentbased instruction, an umbrella term, which refers to the multiplicity of learning objectives. The authors consider the spread of content and language integrated learning (CLIL) programs in various countries.

Martin East contributed a chapter on task-based language teaching (TBLT) and its evolution since the 1980s. Aimed at fostering real language use in L2 classrooms via learners' engagement in tasks, TBLT has yielded positive and consistent results in second language acquisition.

The chapter entitled Professional Communication by Britt-Louise Gunnarsson scrutinizes language for 
specific purposes (LSP), which today is considered as a wide field, covering the general language system in response to specific professional needs and is often referred to as professional discourse or professional communication.

The reviewed book weighs up the advantages and disadvantages of CLIL in the chapter CLIL: A European Approach to Bilingual Education by Tarja Nikula. CLIL is regarded as a key element in the European Union multilingualism policy for bilingual education in Europe, with English or sometimes other languages serving as the language of instruction in nonlanguage subjects. The contributor indicates that CLIL encourages a truly integrated view on language and content.

The chapter Second Language Learning in a Study Abroad Context by Celeste Kinginger outlines research into the phenomenon of studying abroad, which is widely explored in terms of holistic constructs (proficiency, fluency, skills). The author draws readers' attention to the key approaches to language acquisition while studying abroad and looks into potential future directions for research in this area.

The chapter entitled Second Language Literacy Research and Curriculum Transformation in US Postsecondary Foreign Language Education by Per Urlaub is concerned with switching the focus from oral proficiency to the development of literacy competencies. The contributor puts emphasis on the impact on curricula at the postsecondary level in the United States.

The subject of electronic portfolios in foreign language learning is widely explored in the chapter written by Mary Toulouse and Michelle GeoffrionVinci, who present its underpinnings coming from theory and methodology. The chapter brings to the fore the evolution of e-portfolio as a powerful and efficient tool in language study in the historical context over the past 20 years and suggests e-portfolios for assessment practices. The key challenges in e-portfolio implementation are outlined, including necessary changes in the current educational landscape, development of innovative technologies that facilitate portfolio distribution, the need for new pedagogical approaches and methodology based on e-portfolio as an alternative assessment tool.

The next chapter authored by Chantelle Warner touches upon foreign language education in the context of institutional globalization. The author makes a point about an all-rounded and far-fetching influence of globalization on foreign language education. The article provides a detailed account of key issues facing foreign language education at globalized institutions. Among those are the Culture and Language Across the Curriculum (CLAL) movement, the study-abroad practices, the information technologies in foreign language instruction, and the new literacy practices.

The chapter headlined The Role of the National Standards in Second/ Foreign Language Education is written by Sally Sieloff Mangan. The author is concerned with the theme of the goals for language learning set forth by the World-Readiness Standards for Learning Languages, which are known as the $5 \mathrm{Cs}$ : Communication, Cultures, Connections, Comparisons, and Communities. The standards lay foundations for foreign language instruction in the USA. The article overviews issues resulting from over-emphasis on Communication and Cultures in instruction, a tendency for goal-oriented teaching, a limited range of assessment tools and others.

The chapter Network-Based Language Teaching (NBLT) authored by Richard Kern, Paige Ware, and Mark Warschauer outlines two trends in research on NBLT (interactionist second language acquisition models and sociocultural and socio-cognitive theories in NBLT). The article maintains that structure and goals of NBLT are rapidly changing. The research is also focused on online learning in non-classroom contexts and multimodality.

Part Two is extremely interesting and practical, since it sums up the changes brought about by the recent developments in second and foreign language education.

Part Three International Perspectives on Second and Foreign Language Education is organised into eleven chapters and provides a panoramic analysis of second and foreign language education in Australia (by Suzanne Fernandez and Margaret Gearon), in South Africa (by Nikonko M. Kamwangamalu), in the Middle East and North Africa (Mahmoud A. Al-Khatib), in Japan (by Ryuko Kubota), in Canada (by Margaret Early, Diane Dagenais, and Wendy Carr), in the Asia-Pacific Region (by Yuko Goto Butler), in the United States (by Olga Kagan and Kathleen Dillon; by Myriam Met and Adriana Melnyk Brandt).

Part Three starts with the chapter on Learning and Teaching Endangered Indigenous Languages by Leanne Hinton. The author argues that as globalization effects on languages and cultures are getting more pervasive, languages spoken by smaller populations are likely to become extinct. The author states that there is a counter-trend of language revitalization, which is spurred by bilingual education, immersion schooling and adult education programs.

Anne Holmen authored the chapter entitled Parallel Language Strategy. With globalization, researcher and student mobility, many universities in non-English speaking countries have extended the use of English as a medium of instruction and research cooperation. To avoid academic field loss in the national languages, universities seek to strengthen English as well as the national languages for academic purposes through so- 
called 'parallel language strategy'.

Part Four entitled Teacher Preparation and Professional Development starts with the chapter Overseas Training of Chinese Secondary Teachers of English by Daguo Li and Viv Edwards. The authors describe continuing professional development for Chinese teachers of English under the current educational reform.

The Professional Development of Foreign Language Instructors in Postsecondary Education is a chapter by Linda von Hoene. As the title suggests, it highlights the trends and reforms in the field of professional development of teachers of English.

Virginia Zavala authored the chapter Teacher Training in Bilinguial Education in Peru, a country with 49 indigenous languages. The article outlines the ways of preserving an indigenous identity as well as a sense of community in this country.

The next chapter is of special interest to many researchers and teachers of English all over the world. It is headlined Nonnative-Speaking Teachers of English as a Foreign Language and written by Oleg Tarnopolsky. The chapter weighs up the advantages and disadvantages of non-native speakers as teachers of English. The author suggests ways of overcoming disadvantages, discussing how to make best use of all strengths of non-native English teachers.
The basic issues of Task-Based Instruction and Teacher Training are overviewed in the chapter with the same title by Klaus Brandl. The author takes a fresh look at some guidelines for teacher educators regarding the best teacher training practices.

The final chapter of Part Four and the volume is related to Developing Instructor Proficiency in Oral Language Assessment written by Margaret E. Malone. Drawing on examples of a changing language education paradigm, the author highlights that it is crucial to train teachers and refresh their knowledge and skills in language assessment.

Given its wide-ranging and rich content, the volume should therefore prove to be an invaluable and authoritative resource of professional information on various aspects of language education. The writing is clear and fluid, thus facilitating easy understanding of the content. The inclusion of a subject index would help the readers to locate issues of specific interest more easily.

Overall, the third edition of Second and Foreign Language Education is a comprehensive and valuable volume with substantial augmentations over the first edition that would certainly enhance the library of any linguist, university professor, language instructor and student of English. 